ISSN 0258-7122 (Print), 2408-8293 (Online)

Bangladesh J. Agril. Res. 41(2): 377-386, June 2016

\title{
SCREENING OF MUNGBEAN (Vigna radiata L. Wilczek) GENOTYPES UNDER NUTRIENT STRESS IN SOIL
}

\author{
M. A. RAZZAQUE ${ }^{1}$, M. M. HAQUE $^{2}$, M. M. RAHMAN ${ }^{3}$ \\ M. M. BAZZAZ ${ }^{4}$ AND M. S. A. KHAN ${ }^{5}$
}

\begin{abstract}
A pot experiment was conducted at the Bangabandhu Sheikh Mujibur Rahman Agricultural University, Gazipur during kharif season of 2010 to investigate the genetic divergence of some mungbean genotypes under nutrient stress condition using Mahalanobis' statistic $\left(\mathrm{D}^{2}\right)$ and principal component analysis. Analysis of variance showed significant difference for all the characters. Results of multivariate analysis revealed that 200 mungbean genotypes formed five clusters at nutrient stress condition where cluster II had the maximum genotypes (83) followed by cluster I (65), cluster III (30), cluster IV (9) and then cluster V (13). The highest intra-cluster distance was observed between cluster IV containing lowest 9 genotype and cluster V containing 13 genotypes. The highest inter-cluster distance was observed between cluster IV and III and lowest was observed between cluster V and Cluster I. Cluster III had the highest cluster mean for total dry matter, root dry mass, pods per plant, seeds per pod, 1000 seed weight and seed yield. Considering cluster distance and other agronomic performance the genotypes IPSA 1, IPSA 12, IPSA 5 and others genotypes from cluster III may be considered for better performance under nutrient stress condition.
\end{abstract}

Keywords: Mungbean, Nutrient stress, Cluster analysis, Seed yield.

\section{Introduction}

Mungbean (Vigna radiata L.) Wilczek) is an important grain legume grown in the tropical and subtropical regions of the world. It is one of the important sources of protein for both man and domestic animals. Another important feature of mungbean is its ability to fix atmospheric nitrogen in symbiosis with nodule forming rhizobium bacteria. Nutrient stress soil was defined soil contains nutrient below the critical level (FRG, 2005).

Mungbean is a short duration crop and very effective for intensive cropping system. Mungbean can be easily fitted in mungbean $-\mathrm{T}$. aus $-\mathrm{T}$. aman (southern region), mungbean - aman -wheat (north western region) and mungbean - aus -

\footnotetext{
${ }^{1}$ Senior Scientific Officer, Training and Communication Wing, Bangladesh Agricultural Research Institute (BARI), Gazipur, ${ }^{2}$ Professor, Department of Agronomy, Bangabandhu Sheikh Mujibur Rahman Agricultural University (BSMRAU), Gazipur, ${ }^{3}$ Scientific Officer, Training and Communication Wing, BARI, Gazipur ${ }^{4}$ Senior Scientific Officer, Agricultural Research Station, Dinajpur, BARI, ${ }^{5}$ Senior Scientific Officer, Agronomy Division, BARI, Gazipur, Bangladesh.
} 
aman - potato (northern region) cropping systems without considering the fertility status of the soil (Haque et el., 2001). One of the reasons of ignoring soil fertility in mungbean cultivation is its ability to fixation of atmospheric nitrogen (Hardarson and Danso, 1993). However, amount of nitrogen fixed by microbial association varies over different soil types and environmental factors, which might not be sufficient for proper growth and yield formation of mungbean. Most of the researchers evaluated mungbean genotype in optimum soil condition but they ignored low nutrient environments for evaluation of mungbean (Anjum et al., 2006; Akbari et al., 2008; Malik et al., 2002). There exists ample scope to evaluated mungbean genotypes that have inherent capability for producing higher yield under nutrient poor conditions.

The seed yield of mungbean however, remains extremely low in Bangladesh compared with the yield potential (Hossain et al., 2009). One of the major limitations of mungbean productivity is soil fertility as many soils of the country are inherently poor in plant nutrients. This is specially true for char areas where sand particles dominate in soil texture. Under the limitation of soil fertility seed yield of mungbean may be increased either by genetic improvement or by identifying genotypes that are efficient in nutrient accumulation in plants. Therefore, the present study was undertaken with a view to identifying potential ones by screening a large number of mungbean genotypes under nutrient stress soil.

\section{Materials and Method}

A pot experiment was carried out at Bangbandhu Sheikh Mujibur Rahman Agricultural University (BSMRAU), Gazipur during the kharif season (August November) of 2010. The soil used in this experiment belonged to Collected to charland area. Four samples were collected from bulk volume to determine physical and chemical properties of soil. Textural classes of the soil sample were determined by hydrometer method. Organic carbon of the soil sample was determined by wet digestion method to estimate organic matter. Total nitrogen was determined by Kjeldahl method and available phosphorus was determined by percloric digestion method and other nutrient elements were measured as per respective method. Physical and chemical properties of soil are presented in Table 1.

The experimental pots were filled with $12 \mathrm{~kg}$ of soil. No fertilizer was used in the pots to maintain soil as nutrient stress environment. A total of 200 mungbean genotypes were collected from Department of Agronomy, BSMRAU and seeds sown on 31 August, 2010. The experiment was laid out in complete randomized design with four replications. Initially four plants were grown up to measure the physiological characters. One pot was considered as one replication and finally one plant was considered. All agronomic practices like weeding, irrigation and 
mulching were done as and when necessary. Insect pest was controlled by spraying admire @ $0.5 \mathrm{ml}$ litre ${ }^{-1}$ of water during the entire growth period of the crop. The crop was harvested at full maturity. Harvesting was done for pod picking by hand twice one on 31 October and another on 13 November in 2010. In Last harvest dry matter partitioning was measured. Data on plant height, growth, nodule number, yield and yield components of mungbean genotypes were recorded. Plant height was considered as the height from ground level to the longest leaf of the plant. For dry matter determination shoots and roots were oven dried at $70^{\circ} \mathrm{C}$ to constant weight and the dry weights were taken. Yield and yield contributing characters viz. number of pods per plant, seeds per pod and 1000 seeds weight and seed yield per plant were recorded.

Table 1. Physical and chemical properties of the experimental soil before sowing

\begin{tabular}{lccc}
\hline Soil properties & Present value & Critical limit \\
\hline Sand (\%) & 62.23 & - \\
Silt (\%) & 21.77 & - \\
Clay (\%) & 16.00 & - \\
Soil pH & 6.90 & - \\
Textural class & Sandy loam & - \\
Rhizobium/g soil & $4.55 \times 10^{8}$ & - \\
Total N (\%) & 0.05 & 0.10 \\
Available P (ppm) & 0.16 & 8.00 \\
Exchangeable K (meq/100g soil) & 0.85 & 0.08 \\
Available S (ppm) & 7.00 & 8.00 \\
Available B (ppm) & 0.15 & 0.16 \\
Available Zn (ppm) & 0.25 & 0.50 \\
Exchangeable Ca (meq/100g soil) & 14.83 & 2.00 \\
Exchangeable Mg (meq/100g soil) & 1.76 & 0.50 \\
CEC meg/100g soil & 6.904 & $3-7.5$ \\
Organic matter (\%) & 0.536 & - \\
\hline
\end{tabular}

Tocher's method was followed to determine the group constellation. Canonical variate analysis was performed as per Rao (1964) to confirm the results of cluster $\mathrm{D}^{2}$ analysis. Mean data for each character was subjected to both univariate and multivariate analysis. Univariate analysis of the individual characters (analysis of variance) was done by computer using MSTAT-C program. Genetic diversity of 200 mungbean genotypes at nutrient stress was analyzed using GENSTAT 5.13 soft were program. 


\section{Results and Discussion}

The mungbean genotypes showed significant variation for all the morphological characters. Eigen values of 8 principal components are presented in Table 2 . These results revealed that first axes accounted for $56.27 \%$ of the total variation among the genotypes which 8 of these eigen values accounted for $100 \%$. The first two axes of eight Eigen values above the unity accounted for $78.34 \%$ of the total variation. These findings are in agreement with Azam (2012).

Table 2. Eigen values and percentage of variation for corresponding 8 component characters in 200 mungbean genotypes

\begin{tabular}{|c|c|c|c|c|}
\hline $\begin{array}{l}\text { Sl. } \\
\text { No. }\end{array}$ & Principal component axis & Eigen values & $\begin{array}{l}\text { Percentage of } \\
\text { total variation }\end{array}$ & $\begin{array}{l}\text { Cumulative } \\
\text { percentage of } \\
\text { variation }\end{array}$ \\
\hline 1 & Plant height $(\mathrm{cm})$ & 6.0723 & 56.27 & 56.27 \\
\hline 2 & Total dry matter $\left(\mathrm{g}\right.$ plant $\left.{ }^{-1}\right)$ & 1.0231 & 22.07 & 78.34 \\
\hline 3 & Root dry matter $\left(\right.$ g plant $\left.^{-1}\right)$ & 0.7021 & 9.07 & 87.41 \\
\hline 4 & Nodule number plant ${ }^{-1}$ & 0.6107 & 5.07 & 92.48 \\
\hline 5 & pods plant ${ }^{-1}$ & 0.4261 & 4.21 & 96.69 \\
\hline 6 & Seeds pod ${ }^{-1}$ & 0.231 & 2.07 & 98.76 \\
\hline 7 & 1000 seeds weight $(\mathrm{g})$ & 0.0724 & 0.90 & 99.74 \\
\hline 8 & Seed yield $\left(\right.$ g plant $\left.^{-1}\right)$ & 0.0021 & 0.26 & 100.00 \\
\hline
\end{tabular}

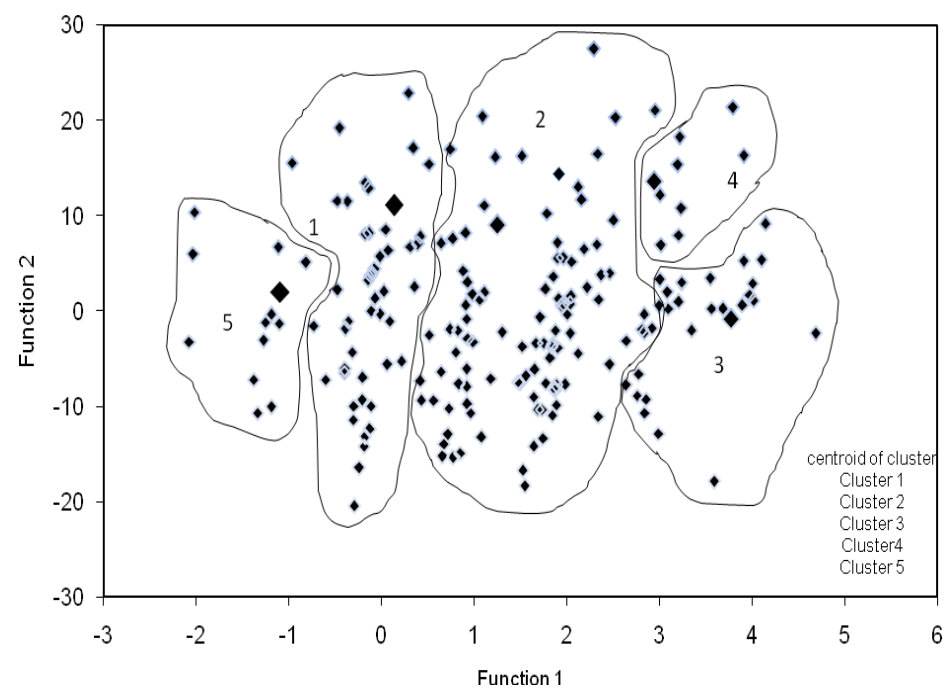

Fig. 1. Scatter distribution of 200 mungbean genotypes based on their principal component scores superimposed with clusters. 
Based on the principal component I and II obtained from the principal component analysis a two dimensional scatter diagram $\left(\mathrm{Z}_{1}-\mathrm{Z}_{2}\right)$ was constructed using component score $\mathrm{I}\left\{\mathrm{Z}_{1}\right.$ (Function 1$\left.)\right\}$ as $\mathrm{X}$ axis and II $\left\{\mathrm{Z}_{2}\right.$ (Function 2$\left.)\right\}$ as $\mathrm{Y}$ axis (Fig. 1). The position of the genotypes in the scatter diagram was apparently distributed into five groups, which indicated that considerable diversity exists among the genotypes.

The inter genotypic distance were used in computation of intra-cluster distances from distance matrix of PCO according to Singh and Choudhari (2001). The intra-cluster distances were not always proportional to the number of the genotypes in the cluster (Table 3 ). In present study the cluster II composed of the largest number (83) of genotypes but their intra-cluster distances were not the highest. The statistical distances represent the index of genetic diversity among the clusters (Biswas et al., 2014). The intra-cluster distances ranged from 0.000 to 26.630. Intra-cluster distances in all clusters were more or less low which indicated that genotypes within the same cluster were closely related. These findings are in conformity with the findings of Datta and Mukherjee (2004), Singh et al. (2005), Marker and Krupaker (2009). Cluster analysis has been used to study the adaptation of genotype to environment by simplifying the pattern responses and by dividing genotypes and environments into more homogeneous categories (Crossa, 1990; Piepho, 1998). It may be said that cluster and scattered distribution mainly classify and group a large number of germplasm into a number of homogenous group.

Table 3. Average inter-cluster and intra cluster (bold) distance $\left(\mathrm{D}^{2}\right)$ of 200 mungbean genotypes obtained by canonical variate analysis

\begin{tabular}{r|cccccc}
\hline Cluster & I & II & III & IV & V \\
\hline I & $\mathbf{1 4 . 4 9 0}$ & & & & \\
II & 13.506 & $\mathbf{1 8 . 7 5 9}$ & & & \\
III & 26.06 & 26.072 & $\mathbf{2 6 . 1 1 0}$ & & \\
IV & 60.514 & 46.715 & 57.676 & $\mathbf{2 6 . 6 3 0}$ & \\
V & 12.23 & 20.12 & 23.24 & 17.36 & $\mathbf{0 . 0 0}$ \\
\hline
\end{tabular}

Canonical variate analysis was done to compute the inter-cluster Mahalanobis $\mathrm{D}^{2}$ values. The intra and inter-cluster distance $\left(\mathrm{D}^{2}\right)$ are presented in Table 3. Results indicate that the highest inter-cluster distances between cluster I and IV (60.514) followed by III and IV (57.676). The higher inter-cluster distances between these clusters indicated to the wide spectrum of variability in the population. However, the highest intra-cluster distance was observed between clusters IV and I which indicated that the genotypes in these clusters were more diverged than those of the others. The clusters V and I (12.23) suggest that a close relationship exist among the genotypes within the clusters. 
The application of non hierarchical clustering using 200 mungbean genotypes were grouped into five different clusters. Cluster II had maximum 83 number of genotypes (Table 4). The clustering pattern of the genotypes under this study revealed that genotypes of the same clustered are not collected from the same district or country. These results are in agreement with the findings of Sharma et al. (1998), Goel et al. (2005) and Sharma and Pawar (2007).

Table 4. Distribution of 200 mungbean genotypes into different clusters,

\begin{tabular}{|c|c|c|}
\hline Cluster & $\begin{array}{l}\text { Total no. of } \\
\text { genotypes in } \\
\text { the clusters }\end{array}$ & Genotypes included in different clusters \\
\hline I & 65 & 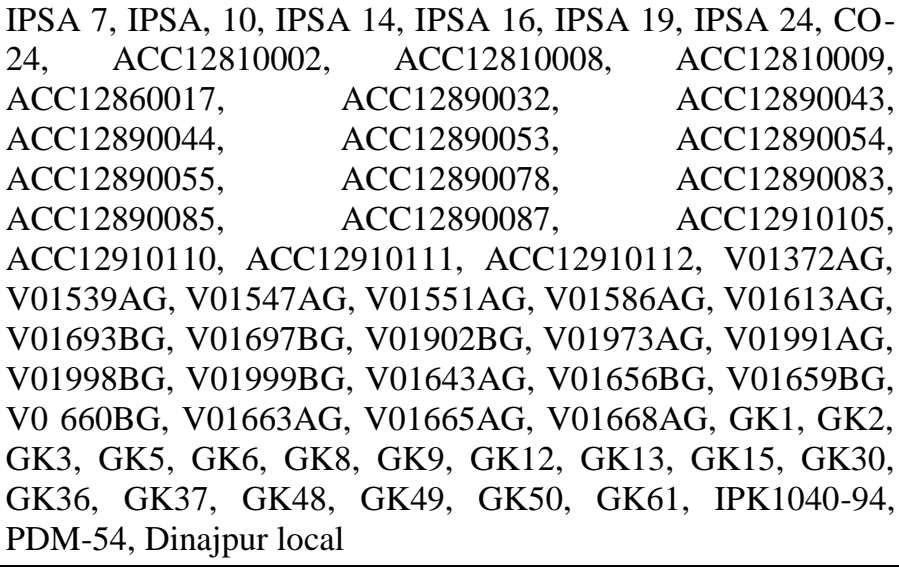 \\
\hline II & 83 & $\begin{array}{l}\text { IPSA 2, IPSA 3, IPSA 8, IPSA 13, IPSA 18, ACC12810004, } \\
\text { ACC12810006, ACC12810010, ACC12840014, ACC12870021, } \\
\text { ACC12880028, ACC12890056, ACC12890071, ACC12890080, } \\
\text { ACC12900102, ACC12910106, V01372BG, V01371AG, } \\
\text { V01396AG, V01549AG, V01575AG, V0 1577AG, V0 1597BG, } \\
\text { V01598BG, V01621BG, V01639BG, V0 1699BG, V01782AG, } \\
\text { V01900AG, V01959BG, , V01995BG, V02008AG, V02103AG, } \\
\text { V02096AG, V02097AG, V01689BG, V01642BG, V01657BG, } \\
\text { V01658BG, V01661BG, V01662BG, V01668BG, V0 1669AG, } \\
\text { V01674BG, V01689AG, V02000AG, V02006AG, V02007BG, } \\
\text { V02073AG, GK 4, GK 7, GK 10, GK 14, GK 16, GK 17, GK } \\
\text { 18, GK 20, GK 28, GK 29, GK 32, GK 33, GK 34, GK 38, GK } \\
\text { 39, GK 40, GK 42, GK 43, GK 46, GK 47, GK 51, GK 52, GK } \\
\text { 53, GK 55, GK 56, GK 57, GK 58, GK 59, GK 60, GK 64, } \\
\text { IPK2558-97, SML-134, ML-267, ML-613, BUmug 2, Barisal } \\
\text { local, BARI Mung-6 }\end{array}$ \\
\hline III & 30 & 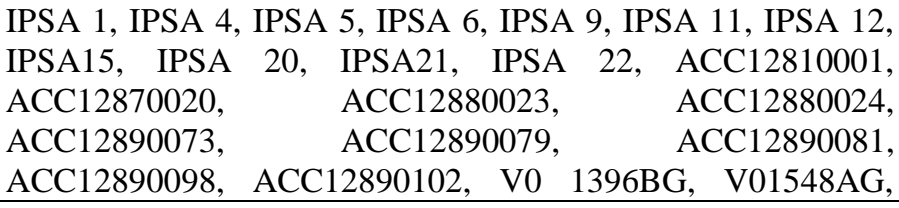 \\
\hline
\end{tabular}


Table 4. Cont'd.

\begin{tabular}{c|c|ccc}
\hline Cluster & $\begin{array}{c}\text { Total no. of } \\
\text { genotypes in } \\
\text { the clusters }\end{array}$ & \multicolumn{1}{c}{ Genotypes included in different clusters } \\
\hline \multicolumn{5}{c}{$\begin{array}{l}\text { V01654AG, GK 11, GK 35, GK 65, PDM-11, SML-12, NM- } \\
\text { 94, Sonamung }\end{array}$} \\
\hline IV & 9 & $\begin{array}{l}\text { V01983BG, V01986BG, V01994BG GK16, GK21, GK22, } \\
\text { GK24 GK 27, Bina mung-5 }\end{array}$ & \\
\hline V & 13 & $\begin{array}{l}\text { IPSA23, ACC12880027, ACC12890084, A01982AG, GK17, GK18, GK20 GK23, GK63, IPK103894, } \\
\text { PUSA9092, BUmug 4 }\end{array}$ & V01995AG \\
\hline
\end{tabular}

Composition of different clusters with their corresponding genotypes and collection site included in each cluster are presented in Table 4. Results of the different multivariate techniques were superimposed with the clusters. The clustering pattern obtained was coincided with the apparent grouping patterns performed by PCA. For that reason it can be said that the results obtained through PCA were established by non-hierarchical clustering

An attempt was made to characterize the individual genotypes in respect of their mean values for different characters with a view to getting the idea weather the genotype having similar characteristics could be disseminates. The intra-cluster mean values for all the 8 characters along with the making of the highest and lowest for each of the cluster are presented in Table 5. The data revealed that different clusters exhibited different mean values for almost all the characters. Plant height had the highest intra cluster means in cluster I followed by Cluster V. The lowest intra cluster means for this trait was observed in cluster IV. The highest total dry matter, root dry mass, nodule number, pods per plant, seed per pod, 1000 seed weight and seed yield was found in cluster III followed by cluster II and the lowest mean value (29.35) was observed for 1000 seed weight in cluster IV.

Canonical variate analysis is an alternative multivariate method that can be used to classify individual genotypes or environments of pre known classes into two or more alternative categories on the basis of a set of measurements (Tabachnick and Fidell, 1989; Afifi and Clark, 1996). Canonical variate analysis revealed that in canonical vector I, the major axes of differentiation, plant height, pods per plant and total dry matter were the important characters responsible for the genetic divergence (Table 6). In vector II, plant height, total dry matter, nodule number and pods per plant had the important role (positive) in both the vectors. Contribution of characters towards the divergence obtained from canonical variate analysis is presented in Table 5. In this methods vector was calculated to represent the varieties in the graphical form (Rao, 1964). The absolute magnitude of the coefficients in the first two canonical vectors also reflects to a great extent, 
the importance of the characters for primary and secondary differentiation. The character which gives high absolute magnitude for vector II, is considered to be responsible for secondary differentiations. Likewise, the characters which give higher absolute magnitude for vector $\mathrm{I}$ is considered to be responsible for primary differentiation. If the same characters give equal magnitude for both the vectors then the character is considered responsible for primary as well as secondary differentiation.

Table 5. Cluster means of eight discriminating variables mungbean genotypes

\begin{tabular}{|c|c|c|c|c|c|}
\hline \multirow[t]{2}{*}{ Characters } & \multicolumn{5}{|c|}{ Cluster } \\
\hline & I & II & III & IV & V \\
\hline Plant height (cm) & $59.65 \mathrm{H}$ & 52.49 & 57.68 & $52.25 \mathrm{~L}$ & 59.35 \\
\hline Total dry matter $\left(\mathrm{g}\right.$ plant $\left.^{-1}\right)$ & 12.28 & $13 . .21$ & $15.91 \mathrm{H}$ & $9.56 \mathrm{~L}$ & 10.24 \\
\hline Root dry mass (g plant ${ }^{-1}$ ) & 1.15 & 1.11 & $1.54 \mathrm{H}$ & $1.05 \mathrm{~L}$ & 1.16 \\
\hline Nodule number plant ${ }^{-1}$ & 17.03 & 17.30 & $20.39 \mathrm{H}$ & $13.0 \mathrm{~L}$ & 14.00 \\
\hline Pods per plant & 14.73 & 19.92 & $25.19 \mathrm{H}$ & $13.01 \mathrm{~L}$ & 14.25 \\
\hline Seeds per pod & 9.39 & 9.15 & $10.45 \mathrm{H}$ & 10.22 & $8.41 \mathrm{~L}$ \\
\hline 1000 seeds weight $(\mathrm{g})$ & 30.59 & 30.65 & $30.77 \mathrm{H}$ & $29.35 \mathrm{~L}$ & 30.37 \\
\hline Seed yield $\left(\right.$ g plant $\left.^{-1}\right)$ & 4.89 & 5.07 & $9.58 \mathrm{H}$ & $3.89 \mathrm{~L}$ & 4.11 \\
\hline
\end{tabular}

Table 6. Latent vectors associated with the first two components for eight characters of mungbean

\begin{tabular}{llll}
\hline \multicolumn{1}{c|}{ SL No. } & \multicolumn{1}{c|}{ Characters } & Vector I & Vector II \\
\hline 1. & Plant height $(\mathrm{cm})$ & 0.02612 & 0.90117 \\
2. & Total dry matter per plant & 0.00840 & -0.00157 \\
3. & Root dry matter per plant & -0.00012 & 0.00928 \\
4. & Nodule number per plant & -0.01827 & 0.06667 \\
5. & Pods per plant & 0.01822 & 0.37847 \\
6. & Seeds per pod & -0.00257 & 0.03077 \\
7. & 1000 seeds weight $(\mathrm{g})$ & -0.00237 & -0.00250 \\
8. & Seed yield $\left(\mathrm{g} \mathrm{plant}^{-1}\right)$ & 0.01242 & -0.14027 \\
\hline
\end{tabular}

In vector $I\left(Z_{1}\right)$ obtained from PCA, the important characters responsible for genetic divergence in the axis of differentiation were total dry matter $(0.0084)$ and pods per plant $(0.0182)$. In vector II $\left(\mathrm{Z}_{2}\right)$, the second axis of differentiation, root dry matter, nodule number and seeds per pod were important because all these character had positive value. Plant height and pods per plant had positive values in both the vectors, which indicated that they were the important component characters having higher contribution to the genetic divergence among the mungbean genotypes and tolerant to nutrient stress condition studied. 


\section{Conclusion}

The results indicated that the plant height and the number of pods per plant had maximum contribution to the genetic divergence among the genotypes. Considering the cluster distance, cluster mean and other agronomic performances the genotypes IPSA 1, IPSA 5, IPSA 12 and other genotypes from cluster III might be considered as better for nutrient stress soil.

\section{References}

Afifi, A. A and V Clark. 1996. Computer aided multivariate analysis. London, Chapman and Hall.

Akbari, N., M. Barani and H. Ahmadi. 2008. Change of grain protein content and correlations with other characteristics under planting pattern and starter $\mathrm{N}$ fertilizer of mungbean (Vigna radiata L. Wilczek). Am. Eurasian J.Agric. Environ. Sci. 4: 306-310.

Anjum, M. S., Z. I. Ahmed and C. A. Rauf. 2006. Effect of Rhizobium inoculation and nitrogen fertilizer on yield and yield components of mungbean. Int. J. Agric. and Biol. 8 : 238-240.

Azam,M. G. 2012. Morphological and Molecular Diversity Analysis in Maize Inbreds, M.S. Thesis Department of Genetics and Plant Breeding, BSMRAU, Gazipur. Pp. 58-59.

Biswas, A., U. Sarker, B. R. Banik, M.M. Rahman and M.A. K. Mian. 2014. Genetic divergence study in salinity stress tolerant maize. Bangladesh J. Agril. Res. 39 (4) : 621-630.

Crossa, J. 1990. Statistical analysis of multivariate trials. Adv. Agron. 44: 55-86.

Datta. D and B. K. Mukherjee.2004. Genetic divergence among maize (Zea mays L.) inbreds and restricting traits for group constellation. Indian J. Genet. 64(3):201-207.

FRG. 2005. Fertilizer Recommendation Guide. Bangladesh Agricultural Research Council, Farmgate, Dhaka-1215

Goel, P., P.K. Sharma and K. Srivasta. 2005. Genetic divergence in an elite germplasm collection of wheat. Crop Improv. 32:114-120

Haque, M. M., M. A. Afzal, A Hamid, M Abu bakr, Q. A. Khaliq and M. A. Hossain. 2001. Improvement variety of mungbean: BU mug 2, Publication no. 21. Lentil Blackgram and Mungbean development pilot project, PRS, BARI. Gazipur.

Hardarson, G and S. K. A. Danso. 1993. Methods for measuring biological nitrogen fixation in grain legumes . Plant and Soil. 152: 19-23.

Hossain, M. A., A. Hamid and Q. A. Khaliq. 2009. Performance of mungbean genotypes (Vigna radiata (L.) Wilczek) under suboptimal and optimal nitrogen levels. Bangladesh Agron. J. 12: 5-15.

Malik, M. A., S. Hussain, E. A. Warruich, A. Habib and S. Ullah. 2002. Effects of seed inoculation and phosphorus application on growth, seed yield and quality of mungbean (Vigna radiata L.) CV NM-98. Int. J. Agri. Biol. 4(4): 515-516. 
Marker, S and A. Krupaker. 2009. Genetic divergence in Exotic maize Germplasm (Zea mays L.) ARPN J. Agril. Biol. Sci. 4: 44-47.

Piepho, H. P. 1998. Methods for comparing the yield stability of cropping system a review. J. Agron. Crop. Sci. 180: 193-213.

Rao, C. R. 1964. Statistical genetic consideration for maintaining germplasm collection. Theor. Appl. Genet. 86: 673-678.

Sharma, P. K., P. K. Gupta and H. S. Balyan. 1998. Genetic diversity in a large collection of wheat. Indian J. Genet. 58: 271-278.

Sharma, V and I. S. Parwar. 2007. Genetic divergence, for yield its components and quality traits in breed wheat. Haryana Agric. Uni. J. Res. 37: 27-31.

Singh, P. K and L.B. Chaudhari. 2001. Genetic divergence in maize (Zea mays L.) J. of Res. Birsa Agricultural University. 13(2) :193-195.

Singh, P. , S. Dass, V. K. Dwivedi, Y. Kumar and O. Sangwan.2005. Genetic divergence studies in maize (Zea mays L.). Annals of Agric Bio-Res. 10(1): 43-46.

Tabachnick, B. G and L S. Fidell. 1989. Using multivariate statistics, Second edition, Cambridge, Harper and Row. 